ISSN $1676-3742$

\title{
O sentido espiritual do cuidado frente à morte: a transcendência do finito
}

\author{
The spiritual meaning of care towards death: \\ transcendence of the finite
}

Renato da Silveira Borges Neto

\section{Resumo}

O artigo pretende mostrar a importância da espiritualidade no processo finito e vital de morrer. A espiritualidade é vista, assim, como um modo de ser do espírito que atravessa todas as atividades do humano e torna-se mais sensível no momento derradeiro, especialmente através do cuidado que permeia este momento.

Palavras-chave: Espiritualidade. Cuidado. Morte.

\begin{abstract}
The article highlights the importance of spirituality in the finite and vital process of dying. Spirituality is seen as a way of being of the spirit that runs through all activities of human and becomes more sensitive in the final moment, especially through the care that permeates this time.
\end{abstract}

Keywords: Spirituality. Care. Death.

\section{Introdução}

O homem é um ser possuidor de individualidade. Só ele tem capacidade de autoconsciência que o deixa - na sua relação com o mundo - em uma posição 
privilegiada ${ }^{1}$. A partir de seu eu, detentor de uma autoconsciência, o homem olha o mundo, as coisas, e põe-se em relação com elas. Ele, no entanto, vai além dessa simples relação: consegue distinguir-se das coisas. Esta capacidade de diferenciar-se é prerrogativa do ser em sua transcendência: ao mesmo tempo em que identifica-se, em sua existência, com seus pares, diferencia-se deles no modo como realiza de forma independente a experiência de sair de $\mathrm{si}^{2}$.

O homem vê no mundo uma outra realidade que não si mesmo. Vê um belo vaso de cristal Sévres, por exemplo, e sabe que ele é algo que não faz parte de si; o belo vaso, porém, não sabe que não faz parte do homem, nem mesmo sabe de si mesmo. Não possui autoconsciência. As coisas - que são desprovidas de uma individualidade, de um eu - podem tão somente ser colocadas em relação, não relacionarem-se. Assim, uma cadeira e uma mesa que estão à venda em uma loja de antiguidades não relacionam-se entre si, mas podem ser colocadas em relação pelo vendedor que vê nelas um conjunto harmonioso. A mesa, sendo um objeto - uma coisa em meio a outras coisas -, não formula juízo sobre a cadeira nem vice-versa, mas o sujeito formula juízo sobre cada uma delas e também sobre ambas, conjuntamente. É neste sentido que só o sujeito pode ser o centro das relações no mundo ${ }^{3}$.

Sujeito e objeto estão dispostos em uma correlação existencial. Mesmo vendo-se como um outro diferente do objeto que está diante de si, o sujeito autoconsciente sabe também de pertencer ao mundo, sabe que encontra-se mergulhado em um contexto que exerce influência sobre si, mas que ele também pode influenciar; sabe, enfim, que é um ser-no-mundo, sem o qual não pode existir. A razão forma uma identidade através do parâmetro da diferença, ou seja, sou eu porque sou diferente dos outros seres. Assim, forma o eu, dando a ele a sua identidade e tornando possível um mundo interior, o mundo do pensar, que Descartes denominou de res cogitans, 'coisa pensada'. Mas a razão, possibilitando a formação do eu através da identidade, também forma o próprio mundo

\footnotetext{
1 "A unidade efetiva do mundo apresenta um caráter concreto só a título de correlato de uma pessoa. Nenhum mundo é mundo concreto, a não ser enquanto mundo de uma pessoa. As diversas regiões de objetividade tornam-se plenamente concretas só enquanto parte de um mundo, o mundo da pessoa. Uma vez que a individualidade da pessoa se comunica ao mundo, que lhe pertence, o mundo que pertence a cada pessoa deve ser também, e necessariamente, um mundo individual, um mundo original e único" (GILES, T.R. História do existencialismo e da fenomenologia. São Paulo: EPU/EDUSP, 1989, p. 161).

${ }^{2}$ Cf. HEIDEGGER, M. Identität und Differenz. Tübingen: Neske, 1957.

3 “...só podem existir objetos para um ser capaz de ter consciência de si” (GILES, T.R. História do existencialismo e da fenomenologia, p. 160).
} 
através da diferença, mundo exterior, das coisas, identificado pela tradição cartesiana como res extensa. A razão está, assim, na base da formação do mundo interior e exterior. É a razão no sujeito e seu reflexo no mundo.

O eu humano - entendido como realidade racional e autoconsciente - sabe que precisa de um mundo para existir. Autoconsciência e consciência de mundo são, também elas, interdependentes. Para que haja autoconsciência é necessária uma consciência do contexto no qual o sujeito se encontra, uma consciência do mundo. Em contrapartida, para que possa haver consciência de mundo é necessária uma autoconsciência plenamente desenvolvida, visto que somente em certos estágios de autoconsciência é possível agir racionalmente sobre o mundo. Um exemplo pode ajudar na compreensão dessa relação: pensemos a um bebê de três meses de idade. Naquele momento, o bebê vive uma fase em que começa a conhecer uma infinidade de coisas no mundo. Até ali, no entanto, o pequeno ainda não conquistou a noção de $e u$, de identidade própria. Possui razão, é um ser racional, mas só posteriormente ele desenvolverá uma verdadeira consciência de si, como ser distinto da mãe e do mundo. Pertence já a uma família, mas saberá que ele próprio não se confunde com ela. Só no futuro, enfim, quando desenvolver-se plenamente, poderá olhar para si mesmo como um ser totalmente diferenciado, olhando o mundo como algo seu, visto sob sua perspectiva, do seu modo e ponto de vista, não obstante a aparente grandeza e complexidade que encontrará diante de si. Daqui nasce a compreensão de que existe uma estrutura ontológica fundamental que está na base de todas as outras estruturas: o ser-aí que se autocompreende como ser-no-mundo.

\section{Espiritualidade: entre a razão psíquica, noética e pneumática}

Muito frequentemente se diz que a fé não é racional e que, portanto, não ter fé é a expressão aprimorada da razão. Ora, mas se alguém afirma ter fé, tal afirmação já é racional tendo em vista tratar-se de um juízo lógico que associa um predicado ("tenho fé") a um sujeito ("eu"). Em outras palavras, o homem é um ser possuidor de razão e o que vem do homem só pode ser racional. Mesmo algo que aparentemente poderia, só com muita dificuldade, ser assumido como racional (o bárbaro assassinato de alguém em um momento de ira, por exemplo), não pode não ser racional; um ato de agressão consiste em uma ação que fere as normas morais e jurídicas estabelecidas nas sociedades contemporâneas, mas continua sendo, mesmo se extremo, um ato racional. Neste sentido, também a espiritualidade é racional. Ela não é a razão, não se 
confundem, mas há, entre elas, uma íntima conexão. Para entender melhor a relação existente entre razão e espiritualidade é necessário antes responder a uma pergunta fundamental: em que esfera da razão se enquadra a espiritualidade? Antes de respondê-la, porém, é importante fazer algumas distinções preliminares sobre a esfera psíquica, noética e pneumática da razão.

A esfera psíquica ( $p s y c h e ̀)$ é a autoconsciência que possibilita construir a própria identidade do homem. É ela que torna possível fazer a experiência do próprio $e u$ em sua relação com o mundo, diferenciando o homem de todos os outros seres. Aponta para as relações mais propriamente psicológicas do ser humano e para o seu mundo interior.

A esfera noética (nous) refere-se à inteligência com sua capacidade de compreender o mundo através dos processos de simples apreensão ${ }^{4}$. Através da identidade constituída na esfera psíquica, capacita o homem para o conhecimento permitindo que se faça a experiência da realidade através da relação do mundo intramental (mundo do eu) com o mundo extramental (mundo das coisas). Trata-se, por fim, da capacidade abstrativa da razão que, através da inteligência, elabora conceitos e juízos lógicos. Aponta para as relações mais propriamente gnosiológicas da mente humana.

A esfera pneumática (pneuma) é aquela que, a partir da consciência de si (esfera psíquica) e da capacidade de conhecer o mundo (esfera noética), possibilita a transcendência de si e do mundo. Esta esfera torna o ser humano capaz de realizar a experiência do eu e do mundo voltando-se sobre si mesmo, mas para além de si mesmo, mostrando que o ser humano não se basta e que, assim, tende às realidades transcendentes, sendo dotado de capacidades intangíveis. Aponta para as relações mais propriamente espirituais do ser humano ${ }^{5}$.

É muito frequente que se tenha uma visão limitada sobre a razão. De modo geral, ela é reduzida ao mero entendimento das realidades tangíveis, ou seja, à esfera noética. Em outras palavras, a razão tornou-se, a partir da modernidade, sinônimo de epistemologia. Por outro lado, não é difícil encon-

4 "É o ato pelo qual nós atingimos, sem nada afirmar ou negar, um objeto inteligível" (MARITAIN, J. A ordem dos conceitos: lógica menor. Rio de Janeiro: Agir, 2001, p. 319 apud SOARES, A.M.M. Lições elementares de lógica. Niterói: Sapientia Fidei, 2011, p. 37).

5 "A pessoa humana não é individualizada pela matéria. É enquanto pessoa espiritual que ela é uma pessoa individual. [...] A pessoa, em sua intimidade, é a tal ponto segredo por natureza, que mesmo um ato de livre comunicação não consegue revelá-la a outro. Pois toda posse finita consiste em duas esferas, a da intimidade e da sociabilidade. A esfera da intimidade é eternamente transcendente a todo conhecimento e a toda estimação possíveis por parte do outro" (GILES, T.R. História do existencialismo e da fenomenologia, p. 160-161). 
trar autores que reduzem a capacidade racional ao conhecimento de si mesmo, das motivações e da intencionalidade humana, aproximando a razão, exclusivamente, da esfera psíquica. Este é um traço marcante na história a partir do evento da Psicanálise.

No que se refere à espiritualidade, houve uma redução de sua compreensão aos conceitos lógicos desenvolvidos na esfera noética. Como já fora referido anteriormente, não é possível separar a razão da espiritualidade, mas é necessário observar que a esfera noética, que se faz presente numa reflexão de espiritualidade, não traduz com exatidão a experiência espiritual do ser humano. Na espiritualidade, a esfera noética revela somente uma busca do conhecimento das realidades transcendentes através de uma experiência regulada, sistemática e guiada por conceitos racionais. É importante compreender que há também na espiritualidade uma esfera que, mesmo sendo racional - como tudo no homem -, se eleva além do genuíno sentido kantiano da razão pura. Essa esfera representa uma dimensão que a própria razão não conhece completamente. Em suas Meditações, Blaise Pascal havia já intuído tal dimensão quando afirmara: "o coração tem razões que a própria razão desconhece"; ; ou seja, haveria na razão razões que ela não teria condições de dar conta, que seriam para ela desconhecidas. A isto chamamos de esfera pneumática, eis a resposta para a questão anteriormente levantada: em que esfera da razão se enquadra a espiritualidade?

\section{O modo de ser do espírito}

Para compreender o genuíno sentido da espiritualidade ${ }^{7}$, é necessário observar o modo de ser na experiência da profundidade que se encontra na trivialidade do intercurso diário, o que Martin Heidegger chamou, com propriedade, de cotidianidade ${ }^{8}$. Isso nos reporta a uma breve história: em uma

${ }^{6}$ PASCAL, B. Pensées. Paris: Éditions du Seuil, 1962, seção 4, p. 277.

7 "O homem, como ser espiritual, tem esse poder de elevar-se acima de sua própria existência, de objetivar não apenas as coisas mas também sua própria constituição fisiológica e psíquica, e cada existência-vivida psíquica particular; ele pode, fundamentando-se num centro que se coloca, por assim dizer, acima do mundo espaço-temporal, objetivar seu próprio corpo e sua alma" (GILES, T.R. História do existencialismo e da fenomenologia, p. 160).

${ }^{8}$ Cotidianidade "é aquela condição na qual o ser-aí, no dia a dia, encontra-se no meio dos entes. Nesta coexistência com os entes, ele se descobre nas idas e vindas que constituem o seu intercurso diário" (SOARES, A. M. M. Retorno ao sentido. Três ensaios sobre a ontologia fundamental de Martin Heidegger. Rio de Janeiro: Real Engenho, 2014, p. 42). Outra importante contribuição para 
certa aldeia japonesa, um jovem, corroído por sua curiosidade provocada pela visita de um monge, quis saber o que era o Budismo. Algum tempo depois, peregrinou até um mosteiro e lá, dirigindo-se ao mestre, disse-lhe: "por muito tempo tenho tentado entender o que seja o Budismo, sua essência. Como és mestre, peço-te que me respondas o que seja o Budismo". O mestre olhando para o jovem com sinceridade, respondeu: "mesmo depois de algum tempo, não sei dizer-te o que é o Budismo". O jovem, irritado, retrucou: "como podes ser mestre e não saber responder-me a pergunta que te faço?". O mestre, sem responder, disse ao jovem: "se queres saber o que é o Budismo, permaneças meditando neste mosteiro por sete anos de tua vida. Se quiseres...". O jovem, desolado, mas mergulhado na curiosidade, resolveu aceitar a proposta. Passados os sete anos o jovem, voltando-se ao mestre, disse-lhe: "depois de sete anos, agora sei dizer a mim o que é o Budismo. Todavia, uma nova questão surgiu-me nesses anos, sobre o que é o budhi (iluminação)". A isto respondeu o mestre: "não sei dizer a ti o que seja o Budhi, mas proponho que aceites ficar em meditação por mais sete anos na pedra oval, sob sol e chuva, frio e calor, compensando-te com as leituras da tradição". O jovem, demonstrando irritação, não resistiu à curiosidade que tinha e aceitou, então, a nova proposta do mestre. Passados sete anos de sua experiência de equilíbrio e leitura na pedra oval, ele retornou ao mestre dizendo: "depois de sete anos, agora sei dizer a mim o que é o Budhi. Mas, durante minhas leituras, ocorreu-me uma questão: para que servem os livros?". A isto o mestre respondeu: "se queres saber para que servem os livros, suba à montanha, coberta da neve, levando contigo somente o necessário e este livro que te dou cheio de sabedoria. Permaneças lá sete dias de tua vida". O jovem, sem demonstrar irritação e inquietude, aceitou prontamente o que o mestre propusera. Iniciou logo a subida à bela montanha coberta pela neve do início de inverno. Chegando ao cimo da montanha, o jovem camponês iniciou uma luta entre o dever de ler o livro e a necessidade de proteger-se, com os braços envolto ao corpo, do rigoroso frio. No segundo dia, não mais resistindo às baixas temperaturas, fez uma pequena fogueira e queimou a única coisa que havia ali com

o entendimento da cotidianidade é dada por Albert Camus na obra O mito de Sísifo (1941). "Sísifo, tendo escapado astuciosamente à morte, foi condenado ao suplício de rolar uma grande pedra ao cimo de um monte donde ela se despencava, devendo o condenado recomeçar incessantemente o trabalho. Era eterna sua condenação" (BUZZI, A.R. Introdução ao pensar. Petrópolis: Vozes, 1972, p. 28). Dessa forma, Sísifo descobre a novidade no mesmo. Ver também HIEDEGGER, M. Sein und Zeit, § 26 apud SOARES, A.M.M. Retorno ao sentido, p. 42. 
ele para ser queimada: o pequeno livro. Após os sete dias, o jovem voltou ao mestre e, com o semblante iluminado, disse: "agora sei dizer a mim para que servem os livros".

A história acima nos reporta a uma condição essencial para a experiência do espírito: a capacidade de sair de si (exodus) movido pela curiosidade (curiositas - procurar saber o porquê; admirar-se). Isto quer dizer que não é possível achar em si mesmo o significado profundo das coisas, além do fato de que só é possível ficar admirado colocando-se para fora do raio de sua própria mira. Em primeiro lugar é necessário perceber que o espírito, movido pela busca do sentido de toda a realidade, transborda para fora de si. A espiritualidade só pode ser compreendida como extravasamento do caminho rumo à profundidade. Quanto mais se quer chegar ao profundo, mais exodus ocorre no ser. O jovem da história não é alguém que, buscando algo fundamental para a sua existência, encarcera-se em si mesmo. Ele sai. Admira-se dos seus questionamentos. É jogado para fora, para fora de sua aldeia, e é levado a buscar a sabedoria que acredita estar encarnada no mestre daquele mosteiro. Em um segundo momento sua busca o faz decepcionar-se: não é o mestre que lhe dará a resposta. A esta altura entendemos que espiritualidade não é uma mera busca por uma resposta que possa resolver uma questão periférica, simplesmente acidental. Trata-se de gastar o tempo no enfrentamento de suas limitações, e a primeira delas é a dificuldade de despojar-se. Quem não se despoja de sua simples razão não consegue mergulhar no profundo. Em outras palavras, quem não deixa para trás suas coisas não consegue fazer êxodo. Afinal, quanto menos se leva, mais longe se vai.

Após decepcionar-se, o jovem precisa decidir. A decisão é um elemento constitutivo do modo de proceder diante da própria vida. Decidir é fazer um corte (de-scindere). O jovem estabelece um corte. Apesar das respostas insuficientes do mestre às suas perguntas, resolve cortar de sua busca a irritação e a inquietude para ir adiante, avançando cotidianamente rumo a uma resposta que não encontrará na aparência dos fatos (meditação no templo, pedra oval, livros). Aos poucos percebe que os instrumentos utilizados em sua via não possuem sentido em si mesmos e, por isso, não podem oferecer a ele o que procura. Na espiritualidade os instrumentos da busca não devem ser respostas

\footnotetext{
${ }^{9}$ Este koan (em japonês), narrativa comum no zen budismo que apresenta aspectos inacessíveis à simples razão, foi elaborado pelo Prof. André Marcelo M. Soares com propósito pedagógico e tem sua inspiração nas formulações atribuídas ao filósofo chinês Sun Tzu (em chinês tradicional). Ver: CHENG, A. História do pensamento chinês. Petrópolis: Vozes, 2008, p. 121-155.
} 
para a própria busca, caso contrário, estaríamos diante de um formalismo espiritual, uma espiritualidade sem espírito.

O jovem da história nos ensina que o caminho espiritual é um apenas ${ }^{10}$, que nos remete ao "apenas" do somente e ao "apenas" do penar da vida cotidiana. Trata-se de um modo de ser cor-res-pondente, isto é, um colocar-se todo inteiro, com o coração (a alma), nas coisas que se faz. Também nos deixa ver que a espiritualidade é um modus intellectus, um transcender a aparência: ultrapassar a estética (aisthesis) para atingir o âmago do ser (ontos). É a materialidade do caminho e da caminhada espiritual que permite o jovem ler dentro (intus leggere) das coisas. Se este caminho fosse imaterial simplesmente tornar-se-ia difícil trilhá-lo. Por outro lado, se fosse simplesmente ôntico, material, não conduziria à profundidade e se transformaria em um psicologismo, levando o indivíduo a si mesmo, como resposta solipsista de uma realidade que está para além dele. O modo de ser do espírito é saída de si, esforço contínuo para distinguir-se do mundo ${ }^{11}$. Somente assim é visível a relação eu-mundo.

\section{A morte além do impessoal}

O professor Soares observa que Sócrates já ensinava que a tarefa de aprender a morrer constitui o sentido fundamental da Filosofia. Portanto, experimentar a vida compreende, dialeticamente, a meditação cotidiana da morte.

É paradoxal, mas só podemos refletir sobre a morte enquanto vivos, do lado de cá, da vida. Não é possível cruzar a linha que separa a vida da morte, não podemos "vivenciar" a morte e voltar para falar sobre ela. É verdade também que, quando se morre se morre sempre para os outros e nunca para si mesmo, ou seja, quando falamos ou escrevemos sobre a morte, para que seja tratada com realismo, sempre tomamos alguém como referencial, sempre nos "apoderamos" do passado de outro que já foi vivo, caso contrário estaríamos tratando de uma abstração, de um conceito e não de uma realidade. Quando abordamos nossa própria morte devemos

\footnotetext{
${ }^{10}$ Cf. HARADA, H. “Apenas apenas”. Grande Sinal 32 (1978).

11 "Modo, em grego, egklisis, significa inclinação para o lado. O ser, ao presentificar-se, se inclina para um lado e se declina para o outro como o mar em ondas. Sempre aparece num modo de ser. Cada vez um modo. Um inclinar-se e declinar-se sem pouso. Os modos não são estados de rigidez" (BUZZI, A.R. Introdução ao pensar, p. 30).
} 
tratá-la como uma possibilidade que, com certeza, irá ocorrer, mas desconhecemos quando e onde. Neste sentido, estamos apenas tratando de um tema, mas não de uma realidade ${ }^{12}$.

Vida e morte estão, portanto, unidas e a morte vai mostrando um papel essencial na vida: a morte torna a vida importante, única. Um exemplo significativo acerca disso pode ser encontrado no romance de Simone de Beauvoir, intitulado Todos os homens são mortais ${ }^{13}$. A autora conta a história, ambientada no século XIII, de um conde chamado Fosca, nascido em 1279, rei da Carmona, cujo reino estava sendo ameaçado pelos genoveses. Diante do desespero da iminência de morte e do desejo de ter tempo para fazer algo realmente útil para a humanidade, Fosca bebe uma fórmula dada por um mendigo já muito idoso e que se revela como sendo o elixir da imortalidade. Fosca torna-se imortal, mas percebe que, diferentemente do que pensava no início, bebeu sua própria condenação. A autora vai aos poucos revelando - mesmo se, no início, mostra um Fosca realizado e cheio de entusiasmo com sua nova condição antropológica - que em seu herói todas as alegrias da vida, as relações sociais, a responsabilidade diante das outras pessoas, vão perdendo peso, até se esvaziarem. Alegrias e sofrimentos nunca são definitivos. Nenhum esforço ou sacrifício do conde Fosca, nenhuma dedicação a que dá provas, nenhuma luta por um ideal tem, para ele, o mesmo significado que para os outros seres mortais. Fosca já não é um ser como os outros. Na vida sem a morte tudo permanece não vinculante, superficial ${ }^{14}$.

Ao longo da história, a morte foi sendo resignificada, às vezes para circunscrevê-la às categorias teológicas e outras para escapar da leitura religiosa. Segundo Soares,

a tradição metafísica ocidental foi acusada inúmeras vezes de reduzir a realidade ao mundo das essências. A verdade e o real foram transformados em conceitos que habitavam esse mundo abstrato onde, segundo Platão, só a alma poderia ter acesso. Tudo neste nosso mundo de realidades sensíveis era considerado cópia, imagem do real, mas não era real, não era verdadeiro. A realidade e a verdade se escondiam nos subterrâneos da alma e por isso a relação com o corpo era mínima, quase nula ${ }^{15}$.

${ }^{12}$ SOARES, A. M. M.; ALMEIDA, S.R.N. de. "Meditatio mortis”. Magis - Cadernos de Fé e Cultura 28 (1998), pp. 59-69.

${ }^{13}$ Cf. BEAUVOIR, S. Tous les hommes sont mortels. Paris: Éditions Gallimard, 1946.

${ }^{14}$ Cf. ARIÈS, P. História da morte no Ocidente. Rio de Janeiro: Nova Fronteira, 2012, p. 31-49.

${ }^{15}$ SOARES, A.M.M.; ALMEIDA, S.R.N. de. Meditatio mortis, p. 61. 
A relação de subordinação do corpo à alma possibilitou, ao longo da Idade Média, a construção de um discurso teológico constituído de uma simbologia escatológica que pouco ou nada tinha em comum com a realidade cotidiana. Deste modo, o discurso teológico sobre a morte alcançou um patamar tão metafísico que com ele não se podia interpretá-la como um processo vital, como um fato cotidiano que advém a cada um dos homens. Neste discurso, o inferno e o céu ocupavam um lugar de destaque e acabavam, por fim, desfocando o elemento que deveria ser principal: o homem, em sua vida, morre. Não se trata de fazer uma crítica ao discurso teológico sobre a morte, mas de perceber a troca que fora feita: a esfera noética substituíra a esfera pneumática do sentido da morte. Em outras palavras, as categorias teológicas, vindas em sua maioria do pensamento grego, parecem ter substituído o cotidiano da vida dos homens e mulheres. Como reação a esta forma de concepção, a modernidade fez substituir o discurso teológico sobre a morte pelo discurso martirológico da causa política:

o que importa é o caráter revolucionário da morte, nada mais. Para um burguês contemporâneo de Danton ou para um militante da Revolução Russa, inspirado nos ideais marxistas, o que importa é morrer para a concretização do projeto político. Trata-se, então, de um caráter político e imanente da morte. O Reino do Céu é, assim, substituído pelo Reino da Terra, onde os critérios da metafisica essencialista cederão lugar aos da ontologia existencialista dos filósofos contemporâneos ${ }^{16}$.

De acordo com Martin Heidegger, comenta Soares:

a morte não é um ponto final da existência e, sim, um elemento constitutivo dela, já que desde o primeiro instante da concepção o indivíduo pode morrer. [...] A existência não é dada ao homem como um caminho bem arranjado no fim do qual está a morte, mas a morte, como possibilidade, atravessa a sua existência: a qualquer momento pode surpreendê-lo ${ }^{17}$.

Diante das constatações acima apresentadas, uma pergunta se faz necessária: como se pode conceber, de modo concreto e positivo, o processo vital de morrer? Para tentar responder a esta questão é indispensável perceber

${ }^{16}$ SOARES, A.M.M.; ALMEIDA, S.R.N. de. Meditatio mortis, p. 62.

${ }^{17}$ SOARES, A.M.M.; ALMEIDA, S.R.N. de. Meditatio mortis, p. 63. 
que muitos buscam uma saída impessoal para fugir da morte como realidade concreta presente na existência cotidiana.

O impessoal transforma a morte num fato, numa ocorrência quase banal; lemos nos jornais os falecimentos como fatos de óbitos; assistimos aos funerais como ocasiões públicas e sociais, regulados por prescrições complicadas sobre a maneira de comportar-se em tais funções. Todos esses ritos e cerimônias, que cercam a morte, têm por finalidade transformá-la num acontecimento público, anônimo. Por esse meio, o impessoal esforça-se com ingenuidade para adiar a morte, apresentando-a como algo que acontece a todo o mundo e, pelo próprio fato, não acontece a ninguém ${ }^{18}$.

Outras vezes, resulta de uma perspectiva impessoal ver a morte não somente como algo que ocorre a outros, mas como algo que, se ocorrer a mim, ocorrerá mais tarde ${ }^{19}$. Através do palavrório banal, o impessoal leva o homem a fazer afirmações tais como: "é certo que a morte vem a cada homem, mas subentende-se que não vem agora para ele" ${ }^{20}$. Como ressalta Elisabeth Kübler-Ross, "a morte constitui ainda um acontecimento medonho, pavoroso, um medo universal" 21 . Além disso, a figura do morto é completamente descaracterizada e desencarnada da realidade histórica: "pouco a pouco, e inevitavelmente, começa a ser tratado como um objeto. Deixou de ser uma pessoa" 22 .

A forma impessoal de conceber a morte resulta em um prejuízo da esfera pneumática da razão humana. Tangenciar este evento significa sonegar à existência humana sua finalidade e suas reais possibilidades. Isso se explica pelo fato de que "morrer é triste demais sob vários aspectos, sobretudo é muito solitário, muito mecânico e desumano" ${ }^{23}$. Neste contexto, o cuidado se torna dimensão importante pelo fato de estabelecer uma relação que nasce do sofrimento físico e psicológico, por um lado, e do resgate do sentido da morte

${ }^{18}$ SOARES, A.M.M.; ALMEIDA, S.R.N. de. Meditatio mortis, p. 64-65.

${ }^{19}$ Cf. SOARES, A.M.M.; ALMEIDA, S.R.N. de. Meditatio mortis, p. 65.

${ }^{20}$ SOARES, A.M.M.; ALMEIDA, S.R.N. de. Meditatio mortis, p. 65.

${ }^{21}$ KÜBLER-ROSS, E. Sobre a morte e o morrer. São Paulo: Martins Fontes, 1996, p. 17.

${ }^{22}$ KÜBLER-ROSS, E. Sobre a morte e o morrer, p. 20. Áries chega a observar que a banalização da morte cria uma promiscuidade que rompe a divisão entre o mundo dos vivos e o mundo dos mortos. "O espetáculo dos mortos, cujos ossos afloravam à superfície dos cemitérios, como o crânio de Hamlet, não impressionavam mais os vivos que a ideia de sua própria morte. Estavam tão familiarizados com os mortos quanto com sua própria morte" (ARIÈS, P. História da morte no Ocidente, p. 49).

${ }^{23}$ KÜBLER-ROSS, E. Sobre a morte e o morrer, p. 19. 
como processo vital, por outro. O cuidado opera, assim, enquanto dimensão pessoal (inerente às relações humanas), como alternativa eficaz para ultrapassar (Überstieg) ${ }^{24}$ a impessoalidade frente à morte.

\section{A dimensão pessoal do cuidado}

Um dia, quando a Preocupação atravessava um rio, viu argila, tomou um pouco e começou a moldá-la. Refletia sobre o que fizera, quando Júpiter entrou em cena. A Preocupação lhe pediu que desse alma àquela forma. Então, uma discussão surgiu entre os deuses. Cada um quis dar seu nome à nova criação. Estavam discutindo quando a Terra se aproximou e insistiu que seu nome fosse dado à nova criatura, visto que ela lhe tinha dado o corpo. Os três chamaram Saturno para julgar a questão. Saturno diz a Júpiter: como tu destes à criatura uma alma, receberás a sua alma depois da morte. E tu Terra, receberás o corpo. E a Preocupação, porque moldou a criatura, possui-la-á enquanto viver. Quanto ao nome será Homo (homem) por ter vindo de Humus (terra). O homem durante toda a sua vida estará sempre possuído pela preocupação ${ }^{25}$.

Tal como Higino apresenta em sua fábula, o homem ao longo de sua existência, enquanto caminha pela terra, estabelece consigo mesmo $(\text { Sorge })^{26} \mathrm{e}$ com os outros (Besorgen $)^{27}$ uma relação de atenção antecipada. Esta característica, que chamamos de cuidado, é fundamentalmente relacional e, portanto, dialógica. Em outras palavras, o cuidado só é possível em uma relação, seja com o próprio eu, seja com os outros.

Estabelecida com o próprio eu, esta relação de cuidado possibilita que o ser humano olhe para si a partir de fora. Isto exige não só uma mudança de

${ }^{24}$ Este termo diferencia-se de Tranzendenz (transcendência). O primeiro corresponde a uma perspectiva imanente. Em outras palavras, trata-se da capacidade que todo ser humano tem, por sua natureza, de - através da razão - avançar sobre si mesmo, ultrapassar-se. Já o segundo termo refere-se à capacidade de perceber-se como finito e, portanto, atravessar-se em direção ao infinito, o que demonstra a natureza ontológica do homem.

${ }^{25}$ GILES, T.R. História do existencialismo e da fenomenologia, p. 104-105 apud SOARES, A.M.M. Retorno ao sentido, p. 48-49, nota 94.

${ }^{26} \mathrm{O}$ termo alemão remete ao cuidado de si. Neste sentido, é todo o cuidado que se tem consigo mesmo numa dimensão mais ampla que aquela do cuidado em saúde.

${ }^{27}$ Refere-se ao cuidado que se tem com o outro por causa de si mesmo. Em outras palavras, é o cuidado interessado, que tem como elemento fundamental a segunda intenção subjacente aos atos humanos e que se opõe ao termo Fürsorge, que significa o cuidado altruístico que se estabelece além da segunda intenção. 
perspectiva, mas uma dimensão autocrítica. No cuidado, a crítica (ou autocrítica) é elemento constitutivo, de tal modo que não é possível cuidar de si ou de outrem sem estabelecer parâmetros criteriosos. Por esse motivo, o cuidado inclui em si o conhecimento como núcleo essencial: a primeira forma de cuidado é, necessariamente, conhecer. Quando se refere ao outro, o cuidado precisa fundamentar-se em uma categoria que se concretize no trato social. A esta categoria podemos chamar de reconhecimento. De acordo com Axel Honneth, que amplia a Teoria do Reconhecimento de Hegel, o reconhecimento não deve ser compreendido como "uma teoria normativa das instituições, nem somente com o objetivo de uma concepção de moral ampliada no plano da teoria da subjetividade, mas sim na perspectiva de uma teoria social de teor normativo" 28 .

O cuidado exige que se reconheça o outro em sua autonomia e em seus anseios de liberdade. É bem verdade que o cuidado metódico, como por exemplo, o de enfermagem, se estabelece a partir de observações empíricas, que reunidas formam um saber científico. Todavia, apesar de sua base experimental, o cuidado deve, por sua natureza inerente, escutar o outro. Esta escuta permite conceber o cuidado de um modo mais abrangente: racionalidade transcendental (esfera noética) de um lado, e racionalidade transcendente (esfera pneumática), de outro. A primeira forma de racionalidade corresponde ao empenho tecnocientífico; já a segunda forma corresponde à dimensão de ausculta vertical, isto é, a capacidade de escutar e reconhecer o outro não só como sujeito de razão e cidadão constituído de direitos, mas como ser possuidor de uma dimensão transcendente e meta-histórica, que o torna aquilo que é.

Objetivamente, o cuidado insere-se na categoria de metron ( $\mu \varepsilon ́ \tau \rho o v)$, caracterizado pela mensurabilidade das realidades tangíveis, que René Descartes identificou como res extensa. Em outras palavras, o cuidado concebido assim, identifica-se com os elementos materiais que o constituem na lida cotidiana, como procedimentos clínicos, estar ao lado do outro, escutar suas necessidades e atender suas solicitações. Subjetivamente, cuidado insere-se na categoria de metrion ( $\mu \varepsilon ́ \tau \rho \imath o v)$, ou seja, daquilo que é adequado e, portanto, justo. Esta categoria revela-se como uma verdadeira hermenêutica do cuidado, que possibilita ler o contexto de cada homem e mulher a partir, não só das necessidades tangíveis (metron), mas, sobretudo, das realidades intangíveis (metrion): os anseios da alma, a angústia e a dor de estar só e doente.

${ }^{28}$ HONNETH, A. Luta por reconhecimento: a gramática moral dos conflitos sociais. São Paulo: Editora 34, 2003, p. 119. 
A relação entre espiritualidade e cuidado acontece enquanto metrion, enquanto se percebe que, com o corpo, sofre todo o homem, que a dor física revela aspectos inusitados e relevantes do sofrimento da alma. Aí salta aos olhos a esfera pneumática que exige daquele que presta cuidado uma escuta atenta à alma que fala no e pelo corpo. Assim, a dimensão espiritual do cuidado ultrapassa a materialidade das formas de cuidado para alcançar a sua totalidade (holos), que abrange as esferas psíquica e noética.

\section{Conclusão}

A espiritualidade é aquela capacidade pela qual o ser humano descobre-se tal qual é na realidade, ou seja, um ser permanentemente - e porque não dizer, ontologicamente - aberto não só a si mesmo e a todos os que o circundam, mas também, e, sobretudo, àquilo que está além de si mesmo, ao transcendente, ao mistério.

A capacidade de abrir-se ao transcendente evidencia a forma que constitui o homem em sua dinâmica no mundo. Gozando de imanência histórica, ele percebe a coincidência de seus questionamentos mais profundos com a impossibilidade de respostas em um plano horizontal. Tal como Nicolau de Cusa, afirma em sua Coincidentia oppositorum ${ }^{29}$, o finito em suas interrogações ontológicas é remetido ao Infinito que, sendo-lhe completamente desconhecido, revela-se como misterium, numinosum e tremendum. Em outras palavras, a espiritualidade não é resposta às perguntas mais profundas, mas uma experiência de solidez na infirmidade ${ }^{30}$. Apesar de caminhar pelo mundo sem saber totalmente de si, dos outros e do transcendente, o homem consegue solidez para encontrar sentido onde o sentido não lhe pode ser totalmente desvelado. Portanto, a espiritualidade é, como Cusa sugere, uma experiência da docta ignoratia ${ }^{31}$ : é saber não saber-se, reconhecer os limites da capacidade de conhecer ${ }^{32}$.

${ }^{29}$ Cf. BOEHNER, P.; GILSON, E. História da filosofia cristã. Desde as origens até Nicolau de Cusa. Petrópolis: Vozes, 1988, p. 562.

${ }^{30} \mathrm{O}$ neologismo denota a insegurança, as dúvidas e os temores que assolam o ser do homem. Não se trata de um evento fortuito, mas de algo inerente à condição humana. Remete-se à noção de angústia (que vem de dentro) e não de temor (que vem de fora).

${ }^{31}$ Cf. CUSANO, N. Della dotta ignoranza. Roma: Signorelle, 1970, p. 67.

${ }^{32}$ Cf. SOARES, A.M.M. Retorno ao sentido, p. 65-66. 
É na experiência da infirmidade que o homem lida com os elementos constitutivos da vida, sobretudo, a morte, que não poderá ser dissociada do processo vital. Assim também será o cuidado que, enquanto disposição de abertura integral ao outro, será sempre limitado por achar-se inscrito no horizonte do tempo e das percepções do humano. Neste sentido não haverá cuidado perfeito. O que deve haver é a delicadeza da alma que percebe-se a si mesma finita em sua essência e finita na materialidade de suas ações. Espiritualidade é, deste modo, o exercício cotidiano de experimentar-se em sua mais profunda essência. Só assim, se compreenderá autenticamente a morte enquanto processo vital e o cuidado enquanto dimensão que atravessa as relações do homem consigo mesmo e com os outros.

\section{Referências Bibliográficas}

ARIÈS, P. História da morte no Ocidente. Rio de Janeiro: Nova Fronteira, 2012.

BEAUVOIR, S. Tous les hommes sont mortels. Paris: Éditions Gallimard, 1946.

BOEHNER, P.; GILSON, E. História da filosofia cristã. Desde as origens até Nicolau de Cusa. Petrópolis: Vozes, 1988.

BUZZI, A.R. Introdução ao pensar. Petrópolis: Vozes, 1972.

CHENG, A. História do pensamento chinês. Petrópolis: Vozes, 2008.

CUSANO, N. Della dotta ignoranza. Roma: Signorelle, 1970.

GILES, T.R. História do existencialismo e da fenomenologia. São Paulo: EPU/EDUSP, 1989.

HARADA, H. “Apenas apenas”. Grande Sinal 32 (1978).

HEIDEGGER, M. Identität und Differenz. Tübingen: Neske, 1957.

HONNETH, A. Luta por reconhecimento: a gramática moral dos conflitos sociais. São Paulo: Editora 34, 2003.

KÜBLER-ROSS, E. Sobre a morte e o morrer. São Paulo: Martins Fontes, 1996.

PASCAL, B. Pensées. Paris: Éditions du Seuil, 1962.

SOARES, A.M.M. Lições elementares de lógica. Niterói: Sapientia Fidei, 2011. 
SOARES, A. M. M. Retorno ao sentido. Três ensaios sobre a ontologia fundamental de Martin Heidegger. Rio de Janeiro: Real Engenho, 2014.

SOARES, A. M. M.; ALMEIDA, S.R.N. de. "Meditatio mortis". Magis -Cadernos de Fé e Cultura 28 (1998), pp. 59-69.

Renato da Silveira Borges Neto

Doutor em Teologia Dogmática pela Pontificia Università

di San Tommaso d'Aquino - Roma

Professor do Instituto Superior de Teologia da Arquidiocese do Rio de Janeiro - ISTARJ

Rio de Janeiro / RJ - Brasil

e-mail: renatosbn@yahoo.com.br

Recebido em: 21/05/15

Aprovado em: 15/09/15 
